\title{
Soigner l'enfant dans les textes médicaux arabes et persans du Moyen Âge
}

Treating children in medieval Arabic and Persian medical texts

Mehrnaz Katouzian-Safadi, Meyssa Bensaad et Jean-Philippe Izard

\section{OpenEdition}

1 Journals

Édition électronique

URL : http://journals.openedition.org/abpo/3706

DOI : $10.4000 / a b p o .3706$

ISBN : 978-2-7535-6539-5

ISSN : $2108-6443$

Éditeur

Presses universitaires de Rennes

Édition imprimée

Date de publication : 16 novembre 2017

Pagination : 203-227

ISBN : 978-2-7535-5674-4

ISSN : 0399-0826

Référence électronique

Mehrnaz Katouzian-Safadi, Meyssa Bensaad et Jean-Philippe Izard, « Soigner l'enfant dans les textes médicaux arabes et persans du Moyen Âge », Annales de Bretagne et des Pays de l'Ouest [En ligne], 124-3 | 2017, mis en ligne le 16 novembre 2019, consulté le 05 janvier 2020. URL : http:// journals.openedition.org/abpo/3706; DOI : 10.4000/abpo.3706 


\title{
Soigner l'enfant dans les textes médicaux arabes et persans du Moyen Âge
}

\author{
Mehrnaz KATOUZIAN-SAFADI \\ Chargée de recherches, laboratoire SPHERE-CHSPAM UMR 7219 CNRS - \\ université Paris 7-Denis Diderot \\ Meyssa BENSAAD \\ Chercheur associée, laboratoire SPHERE-CHSPAM UMR 7219 CNRS - \\ université Paris 7-Denis Diderot \\ Jean-Philippe IZARD \\ Médecin généraliste
}

Que représentent la naissance et les soins à l'enfant pour un médecin dans le monde arabo-musulman médiéval? Les textes que nous examinerons pour répondre à cette question sont écrits principalement en arabe et en persan et proviennent d'une vaste région s'étendant de l'Indus à l'Andalousie (voir fig. 1). Les savoirs qu'ils transmettent se développent dans un contexte historique complexe ${ }^{1}$. Les multiples guerres entre l'empire romain d'Orient (ou empire byzantin) et l'empire perse au vil siècle conduisent à l'affaiblissement du premier et à la chute du second alors que l'on assiste à la stabilisation d'une nouvelle religion, l'islam, et à l'émergence d'un pouvoir conquérant dans la péninsule arabique, dont le centre se déplace rapidement d'abord à Damas, en Syrie, puis à Bagdad, en Iraq. Pendant plus de trois siècles, la langue arabe constitue l'instrument linguistique de ces avancées ${ }^{2}$. Elle favorise le syncrétisme des sciences de cette époque ainsi que leur diffusion en facilitant les échanges entre divers peuples d'ethnies, de religions et de langues différentes ${ }^{3}$. Deux à trois siècles plus tard, parallèlement à l'arabe, d'autres langues, telles que le persan, l'hébreu, le latin ou le turc, ont servi à l'épanouissement des sciences. Le qualificatif " arabo-islamique " reste cependant

1. KATOUZIAN-SAFADI, Mehrnaz, "Les pratiques médiévales aux frontières de l'alchimie et de la médecine ", Ethnopharmacologia, 52, 2014, p. 9-21, en particulier p. 9-11, sur les préambules historiques.

2. Pour les signes de translittération de l'arabe et du persan, se référer au tableau $\mathrm{n}^{\circ} 1$.

3. KatouZIAN-SAFADI, Mehrnaz, "Les pratiques... ", art. cité, p. 10. 
approprié pour désigner une unité géopolitique et intellectuelle favorisée par l'avènement de l'islam. Les traductions de textes scientifiques du grec, du persan, du sanskrit en arabe sont élaborées par des savants ${ }^{4}$ qui associent activités de recherche et de traduction ${ }^{5}$, forgeant ainsi un vocabulaire scientifique. En médecine, l'œuvre du traducteur Hunayn Ibn Ishạa (mort en 877 ) ${ }^{6}$ permet au vocabulaire scientifique de se doter très rapidement de termes précis et communs à l'ensemble de l'empire.

Figure 1 - Carte et période du califat Abbasside, 750 apr. J.-C. (Tiré de AkademieAKTUEL, éd. Bayerische Akademie der Wissenschaften, Ausgabe 03, 2013)

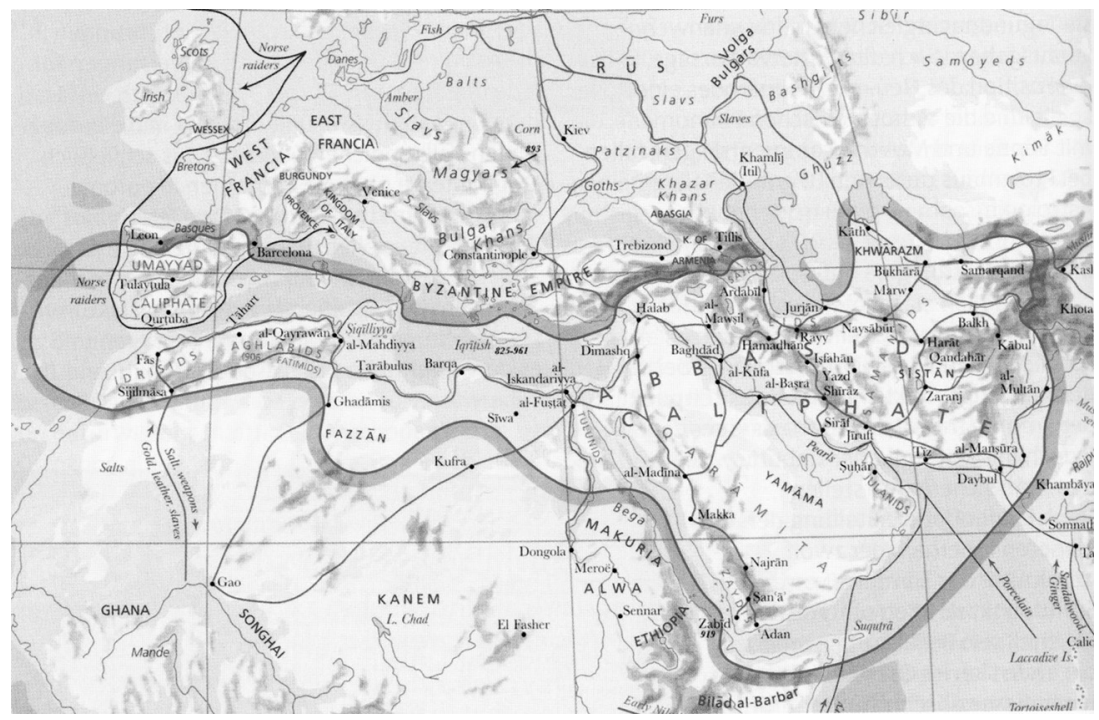

Les textes médicaux révèlent que la plupart des traditions thérapeutiques savantes, issues d'une communauté de médecins, intégraient aussi des traditions locales. Ainsi un antipoison était utilisé spécifiquement dans

4. Gutas, Dimitri, Greek Thought, Arabic Culture. The Graeco-Arabic Translation Movement in Baghdad and Early 'Abbāsid Society $\left(2^{\text {nd }}-4^{\text {th }} / 8^{\text {th }}-10^{\text {th }}\right.$ centuries $)$, Londres/New York, Routledge, 1998; trad. fr. : Pensée grecque, culture arabe : le mouvement de traduction gréco-arabe à Bagdad et la société abbasside primitive (II ${ }^{e}-I^{e} / V^{e} I^{e}-X^{e}$ siècles), trad. Abdesselam ChEDDADI, Paris, Aubier, 2005, p. 50; 197; 202-203.

5. RASHED, Roshdi, "Problems of the Transmission of Greek Scientific Thought into Arabic: Examples from Mathematics and Optics ", History of Science, 27, 1989, p. 199-209. Voir : [http://journals.sagepub.com/doi/abs/10.1177/007327538902700204].

6. Ullmann, Manfred, Wörterbuch zu den griechisch-arabischen Übersetzungen des 9. Jahrhunderts, Wiesbaden, Harrassowitz, 2002, p. 33. L'auteur compare les diverses traductions de Sur les mélanges et les vertus des médicaments simples, œuvre majeure de Galien, qui témoignent de la précision de celle de Ḥunayn Ibn Ishạā. 
la région de Hūzistān, au sud-est de l'Iran actuel. Dans son ouvrage Kitāa al-Manșūrī fí al-țibb ${ }^{7}$, Rāzì le recommande contre les scorpions de cette région ${ }^{8}$. L'ensemble des soins et des rituels qui entourent la naissance d'un enfant possède également des spécificités régionales ${ }^{9}$. Cependant, dans le corpus examiné ici, nous nous intéresserons aux pratiques communes retenues par les auteurs des ouvrages qui ont fait autorité à leur époque et pour les générations suivantes, révélant les modes de circulation et de transmission de ces savoirs.

La vie de l'enfant, dans la société médiévale musulmane, a déjà fait l'objet de quelques études de différents points de vue, médical, légal, théologique, philosophique et éthique ${ }^{10}$. La plupart des travaux antérieurs se basent sur des médecins arabo-musulmans dont les œuvres ont été traduites en latin et qui ont vécu avant le XII ${ }^{\mathrm{e}}$ siècle (Ibn al-Ğazzār, Rāzī, Mağūs̄̄ et Avicenne) ${ }^{11}$. Dans notre étude, tout en citant ces travaux de référence, nous utiliserons d'autres œuvres en arabe ou en persan non traduites en latin, qui ont été largement diffusées, étudiées et lues dans les sociétés médiévales du monde arabo-musulman postérieurement au XII ${ }^{\mathrm{e}}$ siècle. Après une présentation des sources médicales, nous verrons comment l'on soigne l'enfant au quotidien de manière à le maintenir en bonne santé, puis, à travers les écrits de Rāzī, nous évoquerons comment un médecin du monde musulman traitait un enfant en cas de maladies très dangereuses, la variole et la rougeole.

7. RĀZĪ, Kitāb al-Manșūrī fì al-tibb (Le livre de Manșūrī en médecine), éd. et commentaire par Al-Hazim Al-Bakrī al-Șiddîqî, Koweit, Manšūrāt ma'had al-mah̆tūtāt al-'arabīyya, 1987. Dans la suite de l'article, cet ouvrage sera nommé Le livre de Manșūrī.

8. KATOUZIAN-SAFADI, Mehrnaz, « Drug Therapy and Rhazes (865-925): Cultural Heritage and Innovation ", dans Mat, Afife, TEKINER, Halil, ŞEN, Burcu (dir.), The Exchange of Pharmaceutical Knowledge between East and West. Proceeding of the $42^{\text {nd }}$ International Congress for the History of Pharmacy, 8-12 September 2015/Istanbul (Turkey), Istanbul, Eczacılık Tarihi Araştırma Derneği, 2016, p. 403-409.

9. AuBAile-SALlENAVE, Françoise, "Les rituels de naissance dans le monde musulman ", dans BonTE, Pierre, BrISEBARRE, Anne-Marie, GoKalP, Atlan (dir.), Sacrifice en Islam, Espaces et temps d'un rituel, Paris, CNRS, 1999, p. 125-160; GERALD, Marie-Luce, " De la naissance au septième jour : rituels féminins et temps suspendu (tribu berbérophone du Sud-Est marocain) ", Ethnologie française, 2003, p. 131-139. <hal-00430514> [https://hal-descartes. archives-ouvertes.fr/hal-00430514/document].

10. GIL'ADI, Avner, Children of Islam: Concepts of Childhood in Medieval Muslim Society, New York, Springer, 1992. Sur la pédiatrie arabe médiévale : Bos, Gerrit, McVAugh, Michael, Al-Rāzī, On the Treatment of Small Children (De curis puerorum), The Latin and Hebrew Translations, Leyde, Brill, 2017, introduction, p. 9-23. Voir aussi [http://www.gutenberg-e. $\mathrm{org} /$ maclehose/bibliog.html]. Cette bibliographie est divisée en cinq sections, la première concerne une historiographie générale sur l'enfance à l'époque médiévale.

11. De nombreuses œuvres médicales écrites en arabe avant le XII siècle ont été traduites en latin; cet élan de traduction s'est fortement ralenti après cette date. 


\section{Enfance et médecine dans le monde arabo-musulman médiéval}

\section{Les livres de pédiatrie}

Dans le monde musulman médiéval, un ensemble de textes a été spécifiquement dédié à la pédiatrie. Le savant Ibn al-Ğazzār (898-980) a écrit un des plus importants ouvrages sur la manière de traiter et de soigner les enfants $^{12}$. Ce livre est formé de vingt-deux chapitres portant sur les soins à apporter au cours des périodes prénatale, néonatale et postnatale. Les six premiers chapitres ont pour objet le nourrisson, le lait et la nourrice, puis quinze chapitres traitent des maladies des enfants de la tête aux pieds. Le dernier chapitre concerne les problèmes d'éducation et de morale.

Rāzī (mort en 925), le Rhazès des Latins, est un médecin, un alchimiste et un maître de l'enseignement médical. Il vécut principalement à Ray (aujourd'hui près de Téhéran) et Bagdad, villes où il fut directeur de l'hôpital. Ce médecin prolifique a su associer savoir livresque, enseignement et observation des malades ${ }^{13}$. Selon lui, le bon médecin doit lire les livres des Anciens, pratiquer la médecine au chevet des malades et collecter les informations thérapeutiques auprès de la population. Il approuve ou rejette les thérapies anciennes aussi bien que locales et populaires, après expérimentation. Ces observations associées à des commentaires critiques des Anciens ${ }^{14}$ ont permis la conservation livresque des thérapies anciennes et des thérapies locales connues oralement. Il est l'auteur de plusieurs livres de médecine générale et de monographies sur des maladies spécifiques. Son ouvrage le plus célèbre, Le Livre de Manșūrī, comporte une partie théorique et une partie pratique très importantes ${ }^{15}$; il a été traduit en latin et diffusé largement dans sa totalité ou par fragments, comme le chapitre IX concernant la thérapie ${ }^{16}$.

Rāzī a aussi écrit un livre de pédiatrie, Sur le traitement des petits enfants, qui présente des similarités avec celui d'Ibn al-Ğazzār ${ }^{17}$. Cependant, en l'absence de biographie précise des deux auteurs, il est impossible de se

12. IBN AL-ĞAZZĀR, Kitāb Siyāsa al-ṣabyān wa tadbīrihum, éd. Muhammad al-Ḥabīb al-Hīla, Tunis, 1968.

13. KATOUZIAN-SAFADI, Mehrnaz, « La lèpre, la variole, la mélancolie : soigner les déséquilibres du corps ", dans AdAm, Véronique, Revol-MarzouK, Lise (dir.), La contamination : lieux symboliques et espaces imaginaires, Paris, Garnier, 2012, p. 23-51.

14. KATOUZIAN-SAFADI, Mehrnaz, "La cornue et l'alambic, instrument d'analyse et de preuve dans Les doutes sur Galien de Rāzī ", dans Morelon, Régis, HasnaWī, Ahmed (dir.), De Zénon d'Élée à Poincaré, Recueil d'études en hommage à Roshdi Rashed, Louvain/Paris, Peeters, 2004, p. 377-390.

15. RĀZī, Le livre de Manșūrī..., op. cit.

16. JACQUART, Danielle, "Les manuscrits des traductions de Gérard de Crémone : quelques caractéristiques formelles ", dans JAMESSE, Jacqueline (dir.) Les traducteurs au travail, leurs manuscrits et leur méthode (Moyen Âge-Renaissance), Turnhout, Brepols, 2003, p. 207-220; Guenon, Anne-Sylvie, "Le médicament chez Gérard de Solo, médecin montpelliérain du XIve siècle ", Revue d'Histoire de la Pharmacie, 4, 1999, p. 465-474.

17. Bos, Gerrit, McVaugh, Michael, Al-Rāzī, On the Treatment..., op. cit.; les auteurs pensent que Ibn Ğazzār a influencé Rāzī (introduction, p. 10, 1. 9-23). 
déterminer sur la chronologie de la rédaction de leurs œuvres et de savoir lequel a influencé l'autre. Par ailleurs, dans le Livre de la variole et de la rougeole (Kitāb al ğudarī wa $a l$-ḥasba $)^{18}$, Rāzī a déterminé avec précision le diagnostic différentiel de ces deux maladies infantiles graves. Il s'agit d'un des premiers livres dont nous disposions sur l'étiologie de ces maladies et leurs traitements pendant et après les maladies ${ }^{19}$.

\section{D'autres sources médicales sur l'enfant}

Trois autres catégories de livres permettent de saisir plus précisément la manière de traiter l'enfant à cette époque (annexe 2). La première est constituée d'ouvrages sur la conservation de la santé (hifz al-ṣihha) qui attachent une importance particulière aux premiers épisodes de la vie, où le corps est très fragile et les chances de survie sont faibles. La deuxième se compose de livres médicaux qui réservent souvent un chapitre spécifique aux divers âges de la vie. La troisième comprend des livres de pharmacopée qui examinent l'aliment le plus important pour le nourrisson, c'est-à-dire le lait. Ces œuvres ne sont pas isolées, mais appartiennent chacune à un vaste corpus aux caractères communs. Chaque écrivain se situe dans une lignée de savants qui partagent des intérêts et des formes d'expression similaires.

Ibn Buṭlān (mort en 1066), médecin à Bagdad, a écrit le Taqwīm al-Sịhha (La préservation de la santé) ${ }^{20}$, traduit en latin sous le titre Tacuinum Sanitatis, qui a eu une grande fortune en Orient et en Occident. Le Risāla fì širā' al-raqīq wa taqlīb al- 'abìd (Épître sur l'achat et le commerce des

18. RĀZ̄̄, De variolis et morbilis, éd. arabe et trad. latine John CHANING, Londres, 1766; The Smallpox and Measles, éd. et trad. anglaise William A. GREENHILL, Londres, Sydenham association, 1848; Traité de la variole et de la rougeole de Razès, traduction française de la version arabe par Lucien LECLERC et Adolphe LENOIR, Paris, 1866.

19. Katouzian-Safadi, Mehrnaz, Bonmatin, Jean-Marc, " Du diagnostic différentiel aux thérapies prudentes : le traité de la rougeole et de la variole de Râzî ", dans MichAELIDES, Dimitri (dir.), Medicine and Healing in the Ancient Mediterranean World, Oxford et Philadelphie, Oxbow Books, 2014, p. 334-349.

20. IBn BuṬlan, Le Taqwim Al-Ṣiḥha (Tacuinum Sanitatis) d'Ibn Butlan : un traité médical du XI siècle, trad. Hosām Elkhadem, Louvain, Brepols, 1990. 
esclaves), traduit en français par F. Sanagustin ${ }^{21}$, concerne les esclaves qui étaient souvent les compagnons de vie de leur maître, avec des chapitres sur le choix des nourrices qui allaitaient aussi bien leurs enfants que ceux de leurs maîtres.

L'écriture de la prose persane commence vers le XI ${ }^{\mathrm{e}}$ siècle, avec des auteurs célèbres comme Avicenne (mort en 1037). Parmi les auteurs de livres majeurs de médecine en persan, Esmāēil Ğorğānī (1042-1136) rédigea un livre réputé sur les traitements des maladies, dont un chapitre porte sur les soins à accorder à la nourrice ${ }^{22}$.

L'Andalou Ibn al-Baytāar (mort en 1248) est l'auteur d'un célèbre livre de pharmacopée qui a été une référence pour les médecins postérieurs : Kitāb al-ğàmi al-mufradāt (Livre complet des simples), traduit en français par L. Leclerc ${ }^{23}$. Cet ouvrage recense l'ensemble des simples célèbres décrits par les auteurs grecs ou arabes et les simples présents dans d'autres traditions, persane, kabyle, indienne et de diverses régions (Afrique, Asie et une partie de l'Europe).

Le chirurgien Ibn al-Quff ${ }^{24}$ (1233-1286) a rédigé de nombreux livres de médecine et de pharmacie. Cet auteur a suivi sa formation médicale en Syrie chez Ibn Abi Usaybi'ah (mort en 1270), médecin et historien de la médecine. Il a exercé dans différentes villes, notamment à Damas. Son traité sur l'hygiène, Gāmi' al-garad fi hifz al-șihha wa daf' al-marad (Livre complet sur la conservation de la santé et la lutte contre les maladies) ${ }^{25}$, composé de soixante chapitres, décrit l'évolution de l'être humain de la conception à la mort, en prodiguant des conseils d'hygiène adaptés à chaque étape de la vie. Ibn al-Quff consacre de nombreux chapitres à la nutrition, en détaillant les propriétés des différents types d'aliments et de boissons. Il aborde également les effets du bain, des massages et des rapports sexuels sur la santé des individus. D'autres chapitres comprennent des traitements "sur la santé des voyageurs par voie terrestre " ( $f i$ hifz șihhat al-musäfir fì al-barr) ainsi que "sur la santé des voyageurs par voie

21. IBN BuṬLAN, Risāla fì širā' al-raqīq wa taqlīb al- 'abīd ou Epître sur l'achat et le commerce des esclaves, trad. Floréal SANAGuSTIN, Paris, Geuthner, 2010.

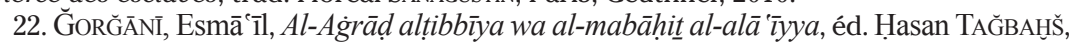
Université de Téhéran, $\mathrm{n}^{\circ}$ 2701, 19, 2 vol., 1385H/2005. Il écrivit un autre ouvrage célèbre, Zakhīrey-e Hwārazmšahī (Le trésor du roi de Hwārazm), dédié à un des rois de la dynastie gouvernante de Hwārazm, la Chorasmie antique, une région qui couvre, au sud de la mer Aral, l'Ouzbékistan d'aujourd'hui et une partie du Turkménistan. À certaines époques de son histoire, cette région a fait partie de la grande Perse ou du grand Iran.

23. IBN AL-BAYȚĀR, Traité des Simples, trad. fr. Lucien LECLERC, Paris, Académie des Inscriptions et Belles Lettres, 3 vol., 1877; réimpr., Beyrouth, 1992. Original arabe :

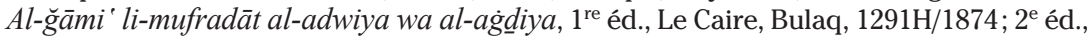
offset, Bagdad, al-Rağab, 1964; $3^{\mathrm{e}}$ éd., Beyrouth, Dar al-kutub Al-ilmiyah, 2001.

24. Hamarnih, Sami Khalaf, "Ibn al-Quff's Contributions to Arab-Islamic Medical Sciences ", Hamdard medicus, 34 (1), 1991, p. 27-36. Voir : [https://www.researchgate.net/ publication/11737260_Ibn_al-Quff's_contributions_to_Arab-Islamic_medical_sciences].

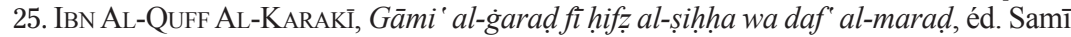
HAMĀRNIH, Ammān (Jordanie), 1989. Le livre est en arabe. Nous avons traduit le titre. 
maritime " (fi hifẓ șihhat al-rākib fi al-baḥr). Cet ouvrage constitue la base de notre article.

En effet, les traités sur l'hygiène forment le socle des savoirs rassemblés pour la conservation de la santé; on y trouve les bases de la médecine savante associée aux habitudes et aux nécessités vitales pour la survie des humains. Mieux que n'importe quel livre, ces textes éclairent l'ensemble des savoir-faire mis en pratique pour sauvegarder l'enfant. Tout en abordant les aspects théoriques, Ibn al-Quff s'applique à donner des informations pratiques pour préserver la santé de l'enfant, de la mère et de la nourrice $^{26}$. Dans le Livre complet sur la conservation de la santé et la lutte contre les maladies, l'hygiène, la diététique, l'exercice physique, la psychologie forment un ensemble d'approches et de pratiques au service de la santé. Cette œuvre a eu une forte influence sur la société médiévale de son époque et les médecins postérieurs.

\section{Du foetus à l'enfant}

\section{Les étapes de la vie}

Ibn al-Quff consacre les sept premiers chapitres de son œuvre au thème de la conservation de la santé dans les premiers temps de la vie :

- Sur la conception de l'embryon (fi keyfìyāt al-takwin al-ğanīn, p. 103-125).

- Sur les âges de la vie et leur tempérament (fi-al-asnān wa amză̆ihāa, p. 16-138).

- Discours sur la conservation de la santé (kalām fì hifž al-șiḥha, p. 139144).

- Sur la conservation de la santé de la femme enceinte (fi hifz șiḥhat al-ḥublā, p. 145-150).

- Sur la conservation de la santé de l'enfant (fi hifz șiḥhat al-tifl, p. 151-4).

- Sur la conservation de la santé de la femme allaitante (fi hifz sihh hat al-murdí'a, p. 155-157).

- Sur la conservation de la santé de l'enfant après le sevrage ( $f i$ hifz șihhat al-ṣabī ba'd al-fițām, p. 155-157).

Dans le premier chapitre, comme dans le reste du livre, Ibn al-Quff compare l'opinion des philosophes et des médecins de l'Antiquité grecque et des savants arabo-persans de l'époque médiévale. Il termine la discussion

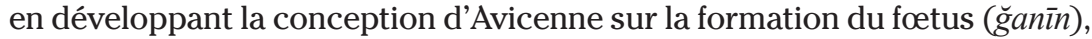
proche de celle de Galien ${ }^{27}$, qui contredit celle d'Aristote. L'auteur cite un

26. L'édition de cet ouvrage sur l'hygiène a été réalisée par Sami Hamarneh, un spécialiste de la médecine et de la pharmacie arabes médiévales et particulièrement d'Ibn al-Quff. Nous bénéficions ainsi d'une excellente édition arabe de l'œuvre : HAMARNEH, Sami, Khalaf, The Physician, Therapist, and Surgeon, Ibn al-Quff (1233-1286): an Introductory Survey of his Time, Life, and Works, Le Caire, Atlas Press, 1974. Pour connaître l'ensemble des travaux de Sami Khalaf Hamarneh en médecine et en pharmacie, voir : [http://0-www. worldcat.org.novacat.nova.edu/identities/lccn-n50018872/].

27. Pour Galien, l'homme et la femme participent tous les deux à la formation du fœetus. 
passage du Canon d'Avicenne (v, 1), où les semences féminine et masculine, désignées par le même terme $(z a r)^{28}$, contribuent toutes les deux à la formation du fœetus. La première, comparée au lait (laban), apporte " la matière " et la seconde, comparée à la présure ('anfiha), contribue en procurant «la forme ${ }^{29}$ ". Toutes les parties du fœetus sont conçues par ces deux semences. Dans les pages suivantes, l'auteur expose les opinions divergentes des savants, des philosophes et des médecins, au sujet de la partie du corps qui commence à fonctionner en premier chez le fœetus, le cœur ou le foie.

Dans le deuxième chapitre, les âges de la vie sont définis avec une terminologie précise. Quatre étapes sont déterminées en fonction des degrés d'humidité et de chaleur du corps qui évoluent au cours de la vie : l'âge de l'enfant (al-nama), de l'adulte (al-šabāb), de la maturité (al-kuhula), de la vieillesse $(a l-s ̌ u y u h a)^{30}$. Au cours de la période de croissance, l'humidité du nourrisson baisse et la chaleur innée (al-harara gariziyya) augmente jusqu'à se stabiliser totalement dans la troisième phase où elle commence à baisser. Chacune des quatre étapes décrites est subdivisée finement selon les évolutions physiques du corps et selon les exigences en alimentation. Pendant deux ans, l'enfant (tifl) se nourrit de lait; après le sevrage (al-fitām) et jusqu'à l'âge de douze ans, le terme préadolescent ( $a l-s a b \vec{\imath})$ qualifie ce corps en évolution. À l'adolescence, les odeurs du corps se modifient car l'humidité s'évapore du cœur et elles se transmettent aux aisselles. Les poils pubiens ('āna) apparaissent grâce à la formation de la semence qui commence à se développer. Les différences entre l'homme et la femme se précisent.

\section{Accueillir le nourrisson}

C'est une sage-femme (qābila) qui aide la mère à accoucher et accueille le nouveau-né. La manière de couper le cordon et les soins à apporter au corps du nouveau-né sont décrits avec minutie ${ }^{31}$. Le corps est soigneusement nettoyé avec du miel, dépourvu de ses impuretés ${ }^{32}$. Les oreilles sont débarrassées des saletés par aspiration, le nez est nettoyé, le rectum et la vessie doivent être massés pour évacuer les matières liquides et fécales. Les membres sont massés avec de l'huile d'olive; les ligaments (mafâșil) et les membres sont frottés avec une poudre composée de bouton de rose

28. IBN AL-QUFF AL-KARAKĪ, Livre complet sur la conservation de la santé..., op. cit., chap. 1, p. 114, 1. 7-16.

29. Malgré la présence de ces concepts " matière " et "forme " d'Aristote, cette façon de concevoir la conception du fœetus par Avicenne est fort loin de celle d'Aristote qui croyait à la primauté du rôle masculin.

30. IBN AL-QUFF AL-KARAKI, Livre complet sur la conservation de la santé..., op. cit., chap. 2, p. 126, 1. 1-6.

31. Ibidem, chap. 5, p. 152-154.

32. Le miel est chauffé et ce qui surnage est éliminé. Ce procédé de chauffage est toujours utilisé lorsque le miel intervient dans la pharmacopée. Il conduit certainement à la perte de certaines qualités, mais il permet d'éliminer des impuretés (dont certaines protéines) que les praticiens doivent craindre. 
écrasé et de myrte. Il faut mettre de temps en temps des gouttes d'huile d'olive vierge dans les yeux. L'enfant est ensuite langé (yuqammaț) en laissant ses mains libres. Il est couché sur le dos, dans un espace sombre, la tête relevée par rapport au reste du corps; il est recommandé de couvrir le lit avec un tissu noir car cette obscurité est bénéfique pour sa vision future et le protège contre l'agitation et la dissipation. Bercer l'enfant lentement est un geste primordial qui équivaut pour le nourrisson à un exercice physique facilitant sa digestion. Les bains du nourrisson doivent être distants d'au moins trois heures par rapport à la tétée et, après le bain, une tétée est bénéfique. En cas de pleurs, il faut d'abord vérifier qu'il n'y a pas dans le lit de bêtes nuisibles, comme des poux ou des puces ${ }^{33}$.

\section{La musique pour la quiétude de l'esprit}

Mais en dehors des soins physiques, un autre aspect est essentiel pour la bonne croissance de l'enfant. Ibn Buțān ${ }^{34}$ accordait une grande importance à la musique pour l'équilibre du corps et de l'esprit humain. Les mélodies (al-alhān), les chants (al-nagiam), les airs et les rythmes harmonieux (al- 'iqā' al-munsağim al-ğamīl) sont pour l'esprit comme des médicaments capables de soigner les corps malades (saqim). L'importance de la mélodie se retrouve chez Ibn al-Quff pour qui la musique est bénéfique pour l'oreille en tant que soin de l'organe de l'ouïe; elle est apaisante pour l'être humain à l'âge mûr et pendant sa vieillesse. Elle a une place particulièrement importante pour le nourrisson et l'enfant, comme l'expérience (al-tağriba) le prouve ${ }^{35}$. De douces chansons mélodiques réconfortent les nourrissons et les petits enfants; elles les détendent (tarawīh) et calment de nombreux maux et maladies.

\section{Le lait et la nourrice}

Cependant, les préoccupations portent d'abord sur le lait, qui assure la survie et la santé de l'enfant, et plus largement sur la nourrice, dont le lien avec l'enfant est très étroit.

\section{La nourrice, le lait et le nourrisson, une chaîne continue}

Les soins directement appliqués à l'enfant concernent ses gencives qui doivent être régulièrement frottées. Pour le reste, le traitement de l'enfant

33. IBN Al-QufF AL-KARAKĪ, Livre complet sur la conservation de la santé..., op. cit., chap. 5 , p. 153 l. 5-6.

34. IBn BuṬlān, Le Taqwim Al-sihha (Tacuinum Sanitatis), op. cit.

35. IBN AL-QuFf AL-KARAKĪ, Livre complet sur la conservation de la santé..., op. cit., p. 13, 1. 2-3; Samī HAMARNEH (voir n. 24) résume les propos d'Ibn Buṭlān : pour les nourrissons, p. 152; pour l'adulte, p. 160; pour les vieillards, p. 163; pour l'ouïe, p. 174. Sur l'importance du rythme et de la musique pour le nourrisson, voir dans ce volume DASEN, Véronique, "Le hochet d'Archytas : un jouet pour grandir". 
passe par celui de la nourrice. L'état du nourrisson dépend de manière directe de celui de la nourrice dont le tempérament et l'état psychique affectent directement le lait qui l'unit à l'enfant.

Si l'enfant a soif, c'est à la mère ou à la nourrice qu'il faut proposer des boissons rafraîchissantes en y associant (mamzī̆g) des graines d'une espèce particulière de concombre (qita $)^{36}$ qui ont la propriété de refroidir le tempérament et dont l'absorption est plus rapide de cette manière.

Lors des diarrhées, fréquentes chez les nourrissons et les enfants, surtout lors des poussées dentaires, la digestion doit être soulagée car le corps de l'enfant ${ }^{37}$ est perturbé par la formation des dents. La nourrice doit être encouragée à prendre des concentrés et des jus de fruits astringents comme les pommes ou les épines vinettes, ou bien du verjus. Les mêmes fruits sont prescrits en cas de vomissements, en y ajoutant la rhubarbe. L'aliment recommandé est le poussin cuit dans les graines de grenade. En cas de constipation, on recommande à la nourrice ou la mère de manger du melon associé au sucre avec de l'oxymel (sikandğabīn). L'insomnie (sahar) de l'enfant peut être soignée si la nourrice prend de la laitue ou respire de l'huile de violette ou bien de l'huile d'amande douce ou de graine de citrouille. Dans de nombreux exemples, les remèdes sont judicieux selon les connaissances pharmacologiques actuelles. Parfois, en parallèle, d'autres traitements sortent du champ de nos connaissances. Ainsi, simultanément à l'absorption d'aliments ou remèdes comme les épinards, le cotonéaster (taranğebinn) et la manne d'hedysarum (šì hisht), le port de la fiente de souris est recommandé ${ }^{38}$. Cette dernière prescription peut surprendre au premier abord, mais elle suit une logique culturelle que l'historien doit reconstruire ${ }^{39}$.

Pour les auteurs médiévaux, le lait et les produits laitiers jouaient un rôle non seulement d'aliment, mais aussi de médicament. Le lait de la mère ou de la nourrice garantissait la survie et la santé du nourrisson, tandis

36. Il s'agit probablement du hīyār tchanbar en persan ou concombre arménien, Cucumis melo var. flexuosus [http://www.plantnames.unimelb.edu.au/Sorting/Cucumis.html\#meloflexuosus]. Ibn Bayțār confirme dans sa pharmacopée les propos de Rāzī sur ses propriétés. Voir IBN Al-BAYṬĀR, Traité des Simples, op. cit., vol. 3, p. 59-60.

37. L'auteur utilise le terme de "nature " (al-tabi 'a), IBN AL-QuFf AL-KARAKĪ, Livre complet sur la conservation de la santé..., op. cit., chap. 5, p. 153, 1. 13.

38. IBN Al-QuFF AL-KARAKĪ, Livre complet sur la conservation de la santé..., op. cit., chap. 5, p. $153,1.9$.

39. Nous suivons ici les recommandations de Mirko Grmek, qui développe et critique avec humour certaines attitudes des historiens des sciences. GRMEK, Mirko, "A Plea for Freeing the History of Scientific Discoveries from Myth ", dans GRMEK, Mirko, CoHEN, Robert, Cimino, Guido (dir.), On Scientific Discovery, Boston, Reidel, 1980, p. 9-42. Sur les aspects irrationnels dans la pharmacopée de l'Antiquité ou du Moyen Âge, voir notamment GaILlARD-Seux, Patricia, "Sympathie et antipathie dans l'Histoire Naturelle de Pline l'Ancien ", dans PALMIERI, Nicoletta (dir.), Rationnel et irrationnel dans la médecine antique et médiévale, aspects historiques, scientifiques et culturels, colloque de Saint-Étienne, 14-15 novembre 2002, Publications de l'université de Saint-Étienne, Mémoires XxVII du Centre Jean Palerne, 2003, p. 113-128. 
que le lait et les produits laitiers provenaient d'un animal pour les autres âges de la vie. Au premier siècle de notre ère, Dioscoride énumère quatre types de lait, de femme, de chèvre, d'ânesse et de chienne ${ }^{40}$. Ibn Bayțār au XIII ${ }^{\text {e }}$ siècle décrit les propriétés du lait de sept animaux ${ }^{41}$ : la chèvre, la brebis, la vache, la jument, la truie, l'ânesse et la chamelle. Chacun possède des propriétés spécifiques, mais ses qualités dépendent de l'alimentation de l'animal à observer afin d'obtenir les qualités requises.

Les proverbes populaires révèlent ce caractère essentiel du lait : « Béni soit pour toi le lait de ta mère " en persan, et "Béni soit le sein que tu as sucé " en arabe ${ }^{42}$. Lors de l'allaitement, les expressions " frère de lait " ou " sœur de lait " reflètent également ce rapport de proximité unique que crée l'allaitement.

\section{Partager le lait}

En persan, la proximité familiale par le lait est appelée " hī̌sawandī riḍa $\bar{l}$ "; le second terme "rid $\bar{a}^{\prime}$ " est un terme arabe qui désigne l'allaitement. Même si dans le texte coranique des passages font allusion au rapport créé entre deux êtres par l'allaitement par une même nourrice, ces lois évoluent dans le temps et dans l'espace. Dans différents pays, comme l'Iran ou la Turquie, les relations créées par l'allaitement sont régies par des textes juridiques déterminés qui évoluent et qui dépassent le cadre de notre travail. Jusqu'à il y a cinquante ans, il était très courant, dans les villages et même dans les villes, pour une mère qui voyageait ou qui était malade, de confier son enfant à une proche (famille, amie, voisine) pour allaiter son enfant, sans rémunération financière. Certaines femmes étaient réputées pour la quantité et la qualité de leur lait et assuraient cette fonction.

Selon Ibn al-Quff, l'expérience montre que le meilleur lait pour le nourrisson est celui de la mère. Il lui convient car il lui ressemble et peut calmer ses maux ${ }^{43}$. L'auteur conseille cependant qu'à la naissance, quelqu'un d'autre allaite l'enfant car le lait de la mère pourrait être "agité " (idțirāa) par les mouvements de la femme lors de l'accouchement. Mais elle doit toujours faire sortir le lait de ses seins ${ }^{44}$. Pour ne pas encombrer l'estomac

40. Dioscoride, Kitāb diusqurīdūs fì hayūla al-țibb, éd. et trad. Mahmūd ṬABĀTABĀē̃, Téhéran, Université de médecine de Téhéran, 2012, vol. 3, p. 51-54. Il s'agit d'une nouvelle édition arabe (accompagnée d'une traduction persane) réalisée d'après la traduction arabe d'Ibn Mehran au XII ${ }^{\mathrm{e}}$ siècle. Cette dernière avait été établie à partir d'un texte syriaque. Pour l'histoire de ces traductions du XII siècle, voir l'édition de 2012, texte arabe, vol. 1, p. 23, l. 5-6; texte persan, vol. 1, p. 45, l. 12-13.

41. IBN Al-BAYṬ̂̄R, Traité des Simples..., op. cit., vol. 3, article no 2007, "Lait (laban)", p. $220-225$.

42. En persan : šir-e madarat halalat bašad شبر مادرت حالت باشد ; en arabe : ya īs al-bez ilā mașsasak يعيش البز الى مصصى.

43. IBN AL-QUFF AL-KARAKĪ, Livre complet sur la conservation de la santé..., op. cit., chapitre 6 , p. $155,1.3$.

44. L'auteur ne précise pas par quel moyen le lait est tiré. 
du nourrisson, il convient de veiller à lui faire prendre de petites quantités de lait et à l'empêcher de sucer trop rapidement. Lorsque la mère n'a pas assez de lait ou que son lait n'est pas de bonne qualité, ou lorsque la mère ne souhaite pas allaiter, par fatigue ( $\left(\mathfrak{d}^{\prime} f\right)$ ou pour son confort (rifāha $\left.a\right)^{45}$, il faut alors chercher une nourrice qui requiert de nombreuses qualités.

Sept conditions sont déterminantes : l'âge, l'aspect de son visage, sa morale et son caractère, l'état de son corps, la qualité de son lait, sa situation; il faut également tenir compte du sexe de l'enfant. L'âge idéal de la nourrice se situe entre vingt-cinq et trente-cinq ans. Les règles courantes de la physiognomonie permettent de déduire l'état du corps et le comportement d'un être. Ainsi, selon cet art, les signes visibles serviront à prévoir l'humeur de la nourrice. Cette science, nommée firāsa en arabe, a été particulièrement mise au service de la médecine par Rāzi $\overline{1}^{46}$. La poitrine doit être large ${ }^{47}$; une belle tenue et un cœur solide sont souhaitables. Il faut tenir compte de la date de l'accouchement de la nourrice et de l'enfant qu'elle a eu; si c'est un garçon, le lait sera plus dense. Le lait doit être blanc, doux et avoir une bonne odeur. La vie de la nourrice, ses boissons, ses mouvements et son repos sont essentiels pour le lait. Ibn Buṭlān dans son livre sur l'achat des esclaves écrit que les meilleures nourrices sont les femmes noires ${ }^{48}$ : les Noirs sont réputés avoir un tempérament chaud et la chaleur au niveau de la poitrine permet la maturation d'un lait de bonne qualité. Il propose un test pour connaître la qualité du lait :

"Déposer une goutte sur un ongle, s'il prend la forme d'une lentille blanche peu fluide et dégage une bonne odeur, il s'agira d'un bon lait ${ }^{49}$. "

L'alimentation de la nourrice suit un code spécifique. Elle ne peut pas consommer des aliments piquants, certains fruits très acides et l'usage de la menthe est surveillé (odeur forte). La pomme et la grenade sont des aliments favorables à sa santé. Après le bain, elle doit prendre de l'oxymel. Le safran est un bon ingrédient lors des repas. Son lit doit être dans un environnement doux; elle doit dormir la tête soulevée et alterner le repos côté gauche et côté droit. Il faut lui éviter l'énervement, la peur et le chagrin.

De manière générale, la femme doit protéger ses seins tout le long de sa vie. Le médecin Ğorğān $\overline{1}^{50}$ prévoit de nombreux cataplasmes à déposer sur les seins pour soigner certains maux (contusions, gonflements par excès de cha-

45. Ibidem, p. 155, l. 11-12.

46. RĀZī, Le livre de Manșūrī..., op. cit., chap. 2, fi al-firāsa, p. 79-107. Cf. WiLGAUX, Jérôme, "La physiognomonie antique : bref état des lieux ", dans Dasen, Véronique, WILGaux, Jérôme (dir.), Langages et métaphores du corps dans le monde antique, Rennes, PUR, 2008, p. $185-195$.

47. Ibn al-Quff utilise ses connaissances en la matière à la fin de son livre, pour découvrir l'état de santé des patients et pour l'achat des esclaves (Ibn al-Quff, 1989, chap. 56 et 57, p. 450-461).

48. IBN BuṬLAN, Risāla fí..., op. cit., p. 132, 206, 233, 248.

49. Ibidem.

50. ĞORĞĀNī̄, Esma ‘̄il, Al-Agrāạd al-tibbìya ..., op. cit., vol. 2, chapitre 19, « Sur les maladies spécifiquement féminines", p. 766-767. 
leur ou de froideur...), le durcissement des seins, ou des blessures. Contre les ecchymoses (terme persan, $k \bar{u} f t e g \hat{\imath})$, une pâte sera ainsi préparée avec un mélange de haricot mungo ${ }^{51}$ et de pépins de raisin de Corinthe ${ }^{52}$, mêlé à de l'eau froide; contre les gonflements dus à l'excès du chaud (āmās-e garm), on fait des compresses de vinaigre et d'eau tiède. Contre les gonflements dus à l'excès de froid ( $\bar{a} m \bar{a} s-e$ sard $)^{53}$, un mélange de céleri et de camomille sert de compresse. Lorsque la femme doit allaiter, la quantité de lait est à surveiller. Pour éviter des faiblesses ou des excès de lait, des aliments ou des aliments-médicaments sont prévus ${ }^{54}$. L'insuffisance du lait est soignée avant tout par le repos. Les remèdes, les aliments et les repas sont adaptés selon le tempérament du corps et les humeurs en déséquilibre.

Au bout de deux ans arrive le temps du sevrage; il est recommandé de le commencer au printemps en introduisant la farine de blé, le lait et le sucre blanc dans l'alimentation. Il convient de diminuer lentement la quantité du lait que l'enfant consomme ${ }^{55}$. À la fin, si l'enfant demande toujours du lait, il faut imbiber le sein avec un produit amer ${ }^{56}$. Après le sevrage ${ }^{57}$, de nombreux conseils sont donnés par Ibn al-Quff. Il faut protéger l'enfant de tout excès de nervosité. Il est parfois nécessaire d'aider l'enfant à marcher à l'aide d'un appareil (āla yamšl $)^{58}$. Ensuite, lorsque l'enfant grandit, la consommation du vin doit être évitée autant que possible pour plusieurs raisons ${ }^{59}$ : cette boisson augmente abondamment l'humidité du corps et

51. En persan, $m a \bar{a} \check{s}$. Le nom scientifique est Vigna radiata (Fabacées); d'abord classée dans le genre Phaseolus, la plante l'a été ensuite dans le genre Vigna.

52. En persan, mawīz.

53. " $\bar{a} m \bar{a} s$ " ou " gonflement " est un substantif d'origine arabe et usité en persan; " garm " et "sard " sont des adjectifs qualificatifs persans qui signifient respectivement " chaud" et " froid".

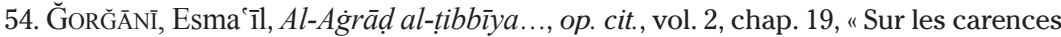
ou les excès du lait ", p. 764-766.

55. IBN AL-QUFF AL-KARAKĪ, Livre complet sur la conservation de la santé..., op. cit., chap. 6 , p. 157.

56. Cette solution était encore pratiquée il y a peu de temps pour sevrer l'enfant dans divers pays, en particulier en Afrique du Nord et au Proche-Orient, où l'on utilisait l'aloès pour rendre les tétons amers. Voir l'article Aloe purpurea : [https://en.wikipe dia.org/wiki/Aloe_purpurea]. Certains journaux donnant des conseils aux jeunes mères évoquent de telles techniques et incitent à ne pas y faire appel. Par exemple, voir le journal en langue persane : 4 avril 2016, l. 11-13, [http://www.farsnews.com/newstext. php?nn=13900703001259]. D'autres sites de conseils aux jeunes mères rappellent cette tradition qui consiste à dégoûter l'enfant des seins; sites en langue française : [http:// www.claude-didierjean-jouveau.fr/2017/02/01/reflexions-sur-sevrag].

57. IBN AL-QUFF AL-KARAKĪ, Livre complet sur la conservation de la santé..., op. cit., chap. 7,

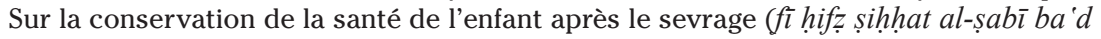
al-fitām), p. 155-161.

58. Ibidem, p. 159, "āla yamšñ ", nom composé en arabe, "'āla " ou " آلة ", signifie " instrument ou outil " souvent fabriqué par les artifices de l'homme pour faciliter une action. Le terme " yam $\bar{s} \bar{\imath}$ ", est une forme verbale provenant de la racine " $m \bar{s} \bar{l}$ » signifiant " marcher".

59. Au début de ce chapitre, ces remarques sur le vin semblent indiquer que l'usage du vin était courant dans la société. 
l'enfant n'en a pas besoin; les vapeurs produites par cet excès d'humidité sont néfastes pour le cerveau; l'humidité favorise la putréfaction; l'ivresse induite par le vin (yusakkar) ne favorise pas le développement d'un bon caractère. Quand l'enfant atteint l'âge de six ans, un éducateur doit être désigné, et à l'âge de douze ans, il faut l'encourager à faire des exercices physiques $^{60}$.

\section{Des maladies foudroyantes de l'enfant : la variole et la rougeole}

Au-delà du quotidien de l'enfant que voit Ibn al-Quff, Rāzī montre comment pouvait être soigné un enfant très gravement malade.

\section{La variole et la rougeole dans le monde arabo-musulman médiéval}

La variole et la rougeole ${ }^{61}$ sont deux maladies effrayantes, douloureuses et souvent fatales. En Inde, où la maladie était endémique, il existait une déesse de la variole ${ }^{62}$ (figure 62). En cas de survie, les séquelles de la rougeole $^{63}$ et de la variole ${ }^{64}$ étaient dramatiques et persistaient toute la vie. Les cicatrices de la variole pouvaient défigurer la personne au point que sa vie sociale devenait difficile, et les séquelles visibles provoquaient l'effroi dans la population.

L'importance de l'impact de cette maladie sur la vie sociale explique le nombre de remèdes proposés par des textes à usage populaire ${ }^{65}$. Ainsi, un

60. Ces remarques pourraient désigner un enfant qui appartient à une classe suffisamment aisée où un éducateur intervient. Cependant, ce point doit être modéré par le fait qu'il pourrait aussi s'agir d'un apprentissage où les charges ne sont pas élevées et ce point doit être complété par les traités sur la sociologie de l'apprentissage à cette époque.

61. Les agents infectieux de la variole et la rougeole sont des virus (pox-virus pour le premier et paramyxovirus pour le second).

62. De nombreuses recettes sont dites indiennes dans les textes médiévaux.

63 . Nous savons aujourd'hui que le virus de la rougeole est responsable de pneumonie (Duke, T., Mgone C.S., "Measles: not just another viral exanthem ", Lancet, 2003, p. 361 ; p. 763-773). Il peut affecter d'autres organes comme le foie et provoquer une hépatite. La rougeole peut conduire également à une encéphalite (une inflammation du cerveau) ou des atteintes du cervelet. La maladie provoque dans $30 \%$ des cas des lésions neurologiques irréversibles : Johnson, Richard T., Griffin, Diane E., HiRsCH, Robert L. et al., "Measles encephalomyelitis - clinical and immunologic studies ", The New England Journal of Medicine, 1984; 310:137-14. Voir : [https://fr.wikipedia.org/wiki/Rougeole\#cite_ ref-12] et la lettre de l'Association des Médecins du canton de Genève : [https://www.amge. ch/2006/12/19/la-rougeole-peut-entrainer-de-graves-sequelles-neurologiques/].

64. La variole peut provoquer l'encéphalite, ainsi que la cécité. Les lésions articulaires risquent de déformer les membres : Breman, Joel G., Henderson, Donald A., "Diagnosis and Management of Smallpox ", The New England Journal of Medicine, vol. 346, $\mathrm{n}^{\circ} 17$, 25 avril 2002, p. 1300-1307, et voir également : [https://fr.wikipedia.org/wiki/Variole cite_note-:7-8].

65. Il est difficile de définir ce terme " populaire " car souvent les médicaments préconisés par les grands médecins lettrés provenaient des usages courants et populaires dans les villes et les campagnes. Nous nous permettons d'utiliser ce terme dans le cas du traité 
manuscrit de pharmacopée non daté, écrit en arabe ${ }^{66}$, énumère des recettes contre les dangers de la vie quotidienne, les maladies physiques ou psychologiques, les animaux venimeux... sans indication de nosologie, ni de diagnostic, ni d'étiologie des maladies. Ce livre est une sorte d'instantané des recettes pour soigner diverses atteintes physiques, dans un espace géographique que nous ne pouvons pas définir pour le moment. La variole y est soignée à l'aide d'une préparation à base de cour d'autruche (chap. 72), la varicelle avec une préparation à base de couleuvre (chap. 126). La lèpre, autre maladie grave et incurable, est aussi soignée à l'aide de la vésicule (le fiel) de l'autruche (chap. 74) ou de la chouette (chap. 128), ou encore avec une préparation à base de viande de marabout (chap. 71). Dans les classifications médiévales arabes, ces remèdes (couleuvre, fiel, autruche) ne sont pas refroidissants, mais de nature chaude, à l'image des fièvres intenses et délirantes à soigner. Il faut rappeler que dans la littérature zoologique arabe, l'estomac de l'autruche est supposé supporter le feu. Le savant al-Ğāhiz ${ }^{67}$ (m. 869), auteur d'une des premières œuvres en zoologie écrites en arabe, Le Livre des animaux (Kitāb al-Haywān), décrit un grand nombre d'observations et d'expériences concrètes ${ }^{68}$. Il expose également les récits entendus et notés par son entourage. Ainsi, il rapporte que l'autruche peut avaler des pierres et des pièces métalliques chauffées ${ }^{69}$.

\section{Variole et rougeole dans les Aphorismes de Rāzī}

D'autres types d'informations sont offerts par les Aphorismes de Rāzì qu'il écrivit à un âge mûr, à l'intention du médecin débutant. Pour lui, il est essentiel de savoir bien interroger le malade, mais parfois le patient ne sait pas décrire son état et ses souffrances, comme il l'explique :

évoqué, à cause du côté pratique et de l'absence de renvoi aux médecins connus ayant écrit des ouvrages de référence.

66. IZARD, Jean-Philippe, Étude d'un manuscrit inédit sur le thème de la pharmacopée arabe (Ms GCM 91 ms In 4º - Bibliothèque municipale de Caen), Master 2, Université de Nantes, 2013.

67. Pour un aperçu de cet ouvrage monumental en sept volumes : AARAB, Ahmed, Étude analytique comparative de la zoologie médiévale : cas du Kitâb al-Haywân d'al-Jâhiz, thèse dirigée par Abdelmalek Essaâdî, Faculté des Sciences de Tétouan, 2001; AARAB, Ahmed, LHERMINIER, Philippe, Le livre des animaux d'Al-Jâhiz, Paris, L'Harmattan, coll. "Acteurs de la Science, 2015.

68. Il était établi à Bassora en Iraq. AARAB, Ahmed, "The Mode of Action of Venom According to Al-Jâhiz ", Arabic Science and Philosophy, 11, 2001, p. 79-89.

69. ĞĀḤIZ (AL-), 'Amr b. Bahr, Kitab al-hayawān, éd. 'Abd al-Salām Muhammad Hārun, Le Caire, Maktabat M. al-Bābī al-Halabī, 1938-1945, vol. 4, p. 320, l. 3-5. Quatre siècles plus tard, nous trouvons une histoire similaire chez un auteur vivant dans la Syrie actuelle, Ibn al-Durayhim al-Mawșīlī (1312-1361). Dans son livre sur les qualités des parties des animaux, il écrit que l'autruche peut digérer du fer chaud parce que son estomac est chaud et fort en digestion (IBN AL-DuRAYHIM AL-MAWȘīLī (1312-1361), Kitāb manafi al haywān. The books of the uses of animals, éd. espagnole par Carmen RUIz BRAVO-VILLASANTE, trad. en anglais par John BoYLAN, trad. en arabe par Muhammad AL-GI'AYDĪ, (d'après le ms arabe 898 de la bibliothèque d'Escurial), Madrid, Adilan, 1981, voir p. 37 (description et qualités de l'autruche). 
"Bien interroger le malade est l'une des choses les plus utiles quand on veut guérir les maladies, une fois que dans sa totalité on a appris l'art médical. Il vaut mieux que le médecin suive son malade et observe ses états car tous les malades ne savent pas exprimer ce qu'ils ressentent. Peut-être que la maladie rend obscur ce que ne conçoit pas aisément le malade même s'il est en pleine possession de sa raison ${ }^{70}$."

Cette observation valable pour un adulte est encore plus justifiée pour un enfant. Une autre difficulté provient de l'état psychologique de la personne malade. Pour Rāzī, le désir et la joie du malade sont des alliés. L'aphorisme 279 expose comment contredire avec délicatesse le patient, surtout un enfant, et le contraindre à faire des régimes alimentaires ou à subir des traitements tout en obtenant son consentement. L'auteur suggère ainsi de donner des petites quantités du produit désiré, même si ce produit n'est pas conseillé pour la personne malade :

" Ne refuse rien brutalement de ce qu'ils désirent, aux fous, aux rois et aux enfants, mais diffère-le, fais-le leur espérer, en donnant l'infime, sinon tu les pousseras à en manger beaucoup en cachette. Ne les habitue pas à de grandes quantités. Fais-leur peur quand ils prennent une grande quantité de ce qu'ils désirent ${ }^{71}$."

Rāzī s'intéresse aux maladies mortelles des enfants qu'il traite dans plusieurs livres. L'aphorisme 32 décrit les conditions propices à ces maladies et suggère quelques précautions simples ${ }^{72}$ :

"Si l'air est miasmatique, aux odeurs nauséabondes, si le nombre des varioles, les cas de rougeole et de peste se multiplient, il faut se réfugier dans de profonds souterrains. Après l'assèchement des lieux, disposer des lits, aménager des pièces à l'abri de l'air miasmatique environnant. Asperger tous les endroits avec du vinaigre, y brûler de l'oliban, des feuilles de myrte et de cyprès. L'emploi fréquent du vinaigre dans les mets et les boissons est recommandé. "

\section{Le livre de la variole et de la rougeole de Rāzī}

Un livre de Rāzī est plus spécifiquement consacré à l'étiologie, au diagnostic et à la thérapeutique de la variole et de la rougeole. Les premiers symptômes de ces deux maladies sont assez proches : fièvres, rougeurs, difficultés pour dormir, douleur dans le dos (voir fig. 3). Si ces maladies existaient aux II $^{\mathrm{e}}$-III ${ }^{\mathrm{e}}$ siècles, Galien n'a pas pu les diagnostiquer. La multiplicité de diverses épidémies pourrait expliquer cette absence de diagnostic ${ }^{73}$ par le médecin de

70. RĀZĪ, Rhazes' Kitâb al-murshid aw al-fusûl (Les aphorismes de Râzî), édition arabe par Albert Zaki ISKANDAR, Madjallât ma had al-maktûtât al- 'arabiyya, vol. 7, fasc. 1, Le Caire, 1980, aphorisme 368. Traduction française : Guide du médecin nomade, trad. El-Arbi Moubachir, Paris, Actes Sud, Sindbad, 1996.

71. Traduction personnelle.

72. RĀZī, Rhazes' Kitâb..., op. cit., p. 58.

73. BIRABEN, Jean-Noël, " Les maladies en Europe : équilibres et ruptures de la pathocénose ", dans GRMEK, Mirko (dir.), Histoire de la pensée médicale en Occident, t. 1, Antiquité et Moyen Âge, Paris, Seuil, 1995, p. 283-310; p. 299. 
Pergame. En effet, l'excès d'autres maladies contagieuses et mortelles et une situation de santé déplorable n'ont pas permis un tel diagnostic. Le livre de Rāzī est le premier livre complet en arabe connu des historiens à ce jour sur ce sujet. Les annexes 3 et 4 résument schématiquement les connaissances actuelles et les propositions de Rāzī. Celui-ci explique selon les théories physiologiques de son temps pourquoi les enfants en bas âge sont rapidement atteints et pourquoi le danger est grand. Ses explications sont fondées sur la nature plus humide et chaude des petits enfants, vision partagée par les médecins de l'Antiquité et de la période médiévale. Rāzī soigne la variole et la rougeole par le rafraîchissement, un traitement qui s'écarte de celui prescrit jusqu'au XVIII ${ }^{\mathrm{e}}$ siècle par de nombreux médecins qui préféraient au contraire réchauffer le corps. Dans le traitement par réchauffement, le corps était entièrement enveloppé, sans laisser de circulation d'air, ce qui provoquait généralement une surinfection des boutons transformés en plaies purulentes et des souffrances extrêmes; Louis XV serait mort dans de telles conditions le 10 mai 1774, de la maladie et d'une grave septicémie ${ }^{74}$.

Selon Rāzì, les aspects psychologiques sont très importants lors des traitements. L'absence de sommeil, les fièvres élevées et les cauchemars qui en résultent provoquent de grandes tristesses et détresses qui sont plus fortes pour la rougeole que pour la variole ${ }^{75}$. L'ensemble du corps doit être traité. Il faut commencer par apaiser l'enfant par la douceur de la voix, par les refroidissements et par le maintien du malade dans un espace frais, peu lumineux et aspergé d'eau de rose. Tous les aliments échauffants sont évités (lait, vin, dattes, miel...). L'eau fraîche sert à refroidir le corps et sa boisson est encouragée. Si la rougeole est plus dangereuse par ses fièvres excessives, la variole attaque les yeux et le risque de cécité est grand. Rāzī préconise de nombreux traitements pour préserver les yeux. Dans ses notes personnelles, il signale que c'est ainsi qu'il a pu gagner la confiance de l'entourage d'une personne malade ${ }^{76}$. Le traitement des pustules par leur nettoyage et la propreté de l'environnement, contenant des parfums et des éléments comme le camphre et le santal, devait apaiser ses jeunes patients, en diminuant la surinfection des boutons et en évitant les délires. Le succès du traitement préconisé par Rāzī est aussi associé au suivi attentif de l'évolution de la maladie et des soins répétés dont témoignent les récits de malades. Cependant, Rāzī reste conscient des difficultés pour mâ̂triser ces maux et ces fièvres indomptables. C'est pourquoi il condamne toute précipitation dans le jugement et dans les traitements de la rougeole et de la variole; en cas de doute, il ordonne au médecin d'admettre son ignorance, de ne pas agir et d'attendre des signes corporels pouvant lui indiquer le chemin.

74. DARMON, Pierre, La variole, les nobles et les princes : la petite vérole mortelle de Louis XV: 1774, Bruxelles, Éditions Complexes, 1989.

75. Katouzian-Safadi, Mehrnaz, Bonmatin, Jean-Marc, " Du diagnostic... ", art. cité, p. 11.

76. Ibidem, p. 9 . 
Figure 3 - Miniature persane du XVII siècle, préparation d'un remède pour un enfant atteint de la variole

(Bilbiothèque de l'université d'Istanbul (Turquie). Expiración GARCíA-Sánchez,

"Parfums d'al-Andalus ", dans GRASSE, Marie-Christine (dir.), Une histoire

mondiale du parfum : des origines à nos jours, Paris, Somogy, 2007, p. 116-119, p. 117. [http://digital.csic.es/bitstream/10261/26093/1/Parfums\%20d'al-Andalus_EGarcia.pdf])

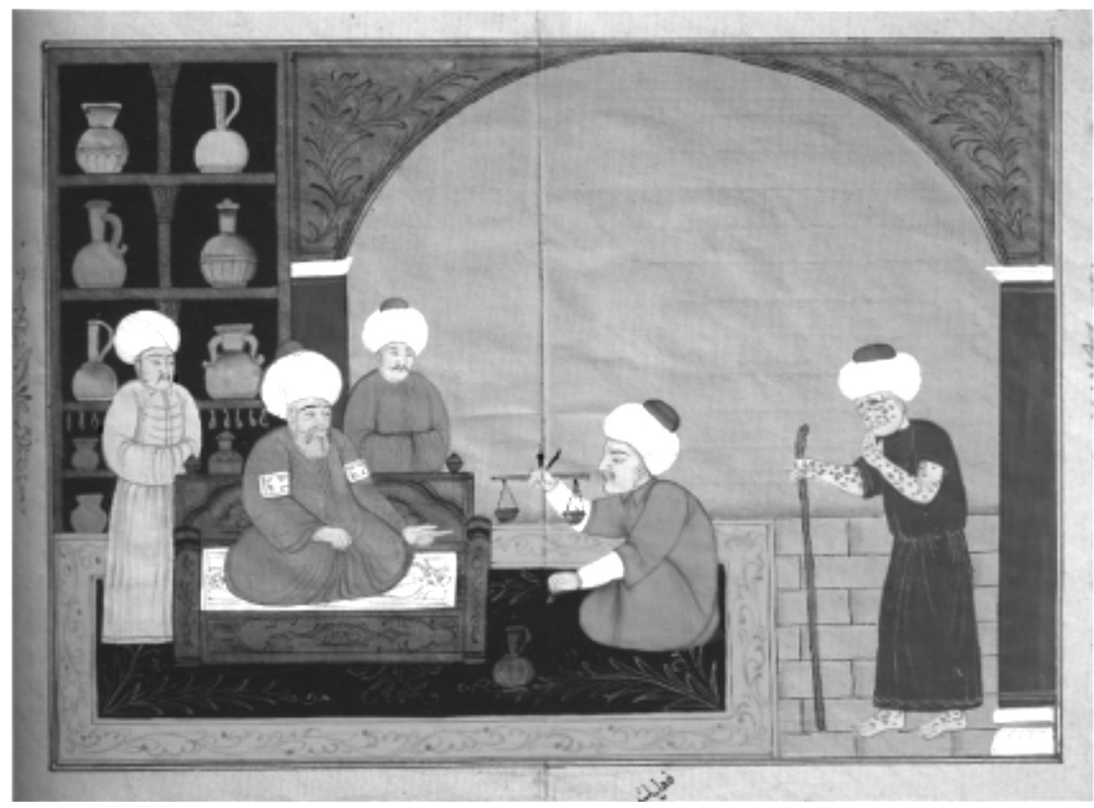

Les textes de Rāzī décrivent l'approche d'un médecin confirmé dans les sociétés médiévales des grandes villes comme Bagdad, Ray, Damas ou Le Caire. Il est l'exemple d'un médecin partisan d'une lecture des textes savants des anciens (grecs ou arabes) associée aux observations au chevet des malades. L'examen du livre d'Ibn al-Quff nous a servi de fil conducteur pour accompagner l'enfant de sa naissance à l'âge de douze ans. Les pratiques décrites étaient apprises et transmises principalement par les femmes du métier. Ses traités éclairent ainsi l'ensemble des soins procurés à un enfant par des soignantes dès l'accouchement. Les témoignages textuels ou picturaux relatifs à cet univers féminin sont encore rares. Ces pratiques étaient transmises par l'observation minutieuse des usages quotidiens inscrits dans les habitudes locales; elles se transmettaient de bouche à oreille, dans l'intimité des maisons, des chambres et des bains. À côté des livres savants écrits par des médecins et des pharmacologues, d'autres types de témoignages historiques pourraient apporter des informations complémentaires, comme l'étude des proverbes, des amulettes pour des 
vœux de bonheur et contre le mauvais œil. Les contes pour enfant, la place de l'enfant dans la littérature, la culture matérielle de l'enfant sont également des sources susceptibles d'apporter des éléments pour mieux apprécier les rapports de l'enfant avec son milieu. Des observations sur le terrain dans les pays du Proche-Orient ou d'Afrique du Nord, sont d'une grande richesse car nous sommes parfois surpris de la conservation de certains gestes qui échappent à l'écriture. Ibn Buṭlān a ainsi passé une grande partie de sa vie à Bagdad. Ibn al-Quff vivait en Syrie et souvent à Damas et a prescrit de masser le corps du nourrisson avec de l'huile d'olive. Pour visualiser comment ces gestes se concrétisent, il est possible encore de nos jours de voir la manière de masser le petit corps du nourrisson en entrant dans l'intimité des maisons et en fréquentant les grands-mères qui ont survécu aux guerres et qui maintiennent une tradition qui rappelle l'amour, l'effort pour vivre et contrer la mort. De telles enquêtes sont impossibles à faire pendant les guerres. Ces guerres nous privent des manuscrits, des sites archéologiques, mais surtout elles nous privent de la vision vivante du passé et de ce que l'humanité partage de manière archaïque, c'est-à-dire la survie de l'espèce humaine. Toutes ces recherches et ces approches sont 
Mehrnaz KatouZIAN-SAFADI, Meyssa BensAAD, Jean-Philippe IZARD

\section{Annexe 1 - Translittération adoptée pour l'arabe} et le persan dans cet article

\begin{tabular}{|c|c|c|c|}
\hline $\begin{array}{c}\text { Caractères } \\
\text { communs aux } \\
\text { alphabets arabe } \\
\text { et persan }\end{array}$ & $\begin{array}{c}\text { Translittération } \\
\text { internationale } \\
\text { arabe }\end{array}$ & $\begin{array}{l}\text { Persan : carac- } \\
\text { tères supplémen- } \\
\text { taires }\end{array}$ & $\begin{array}{c}\text { Translittération } \\
\text { persane dans cet } \\
\text { article }\end{array}$ \\
\hline i & , & Idem & Idem \\
\hline 1 & $\overline{\mathrm{a}}$ & /I & /I \\
\hline 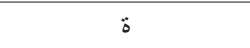 & $\mathrm{a}$ & $/ /$ & $/ /$ \\
\hline$\dot{H}$ & $\underline{\mathrm{t}}$ & $/ /$ & $/ /$ \\
\hline ج & $\breve{g}$ & /I & // \\
\hline$\tau$ & h & // & /I \\
\hline$\dot{\tau}$ & $\underline{h}$ & // & // \\
\hline$\dot{j}$ & $\underline{\mathrm{d}}$ & $/ /$ & $/ /$ \\
\hline ش & $\check{s}$ & /I & // \\
\hline ص & ș & // & // \\
\hline ض ض & de & // & /I \\
\hline$b$ & $t$ & // & /I \\
\hline ظ & $\mathrm{z}$ & // & // \\
\hline$\varepsilon$ & ‘ & /I & /I \\
\hline$\dot{\varepsilon}$ & $\dot{\mathrm{g}}$ & // & // \\
\hline ق & $\mathrm{q}$ & II & /I \\
\hline 9 & $\overline{\mathrm{u}} / \mathrm{w}$ & /I & // \\
\hline \multirow[t]{6}{*}{ ي } & $\overline{1}$ & // & /I \\
\hline & & $\ddot{\varphi}$ & $\mathrm{p}$ \\
\hline & & ह & tch \\
\hline & & j & $\mathrm{j}$ \\
\hline & & 3 & $\mathrm{~g}$ \\
\hline & & Voyelle courte & $\mathrm{e}$ \\
\hline
\end{tabular}


Soigner l'enfant dans les textes médicaux arabes et persans du Moyen Âge

\begin{tabular}{|c|c|c|c|c|c|c|}
\hline 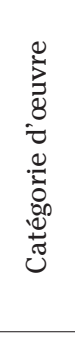 & 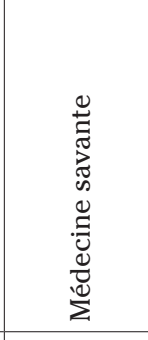 & 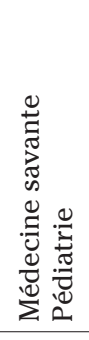 & 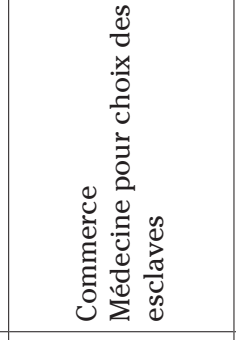 & 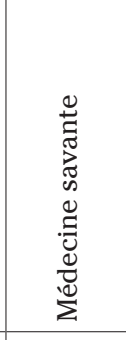 & 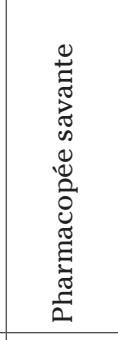 & 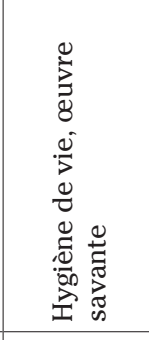 \\
\hline 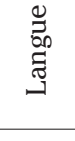 & $\begin{array}{l}0 \\
\widetilde{\widetilde{J}} \\
\tilde{\sigma}\end{array}$ & $\begin{array}{l}0 \\
\text { స్ } \\
\widetilde{\sigma}\end{array}$ & 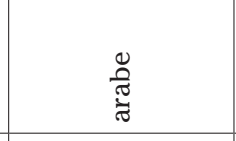 & 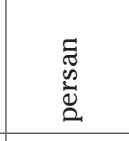 & $\begin{array}{l}0 \\
\text { స్ } \\
\text { స్ }\end{array}$ & $\begin{array}{l}0 \\
\text { స్ } \\
\text { స్ }\end{array}$ \\
\hline 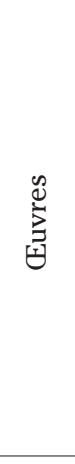 & 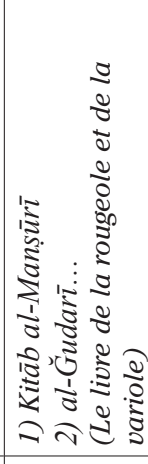 & & 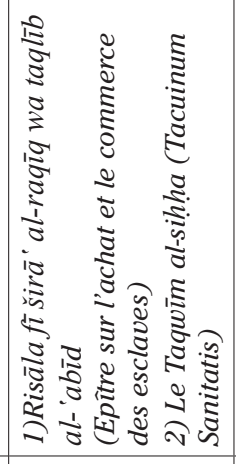 & 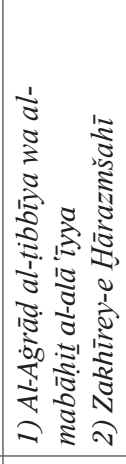 & 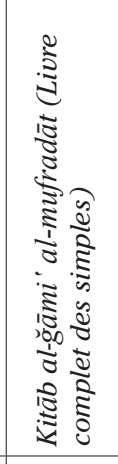 & 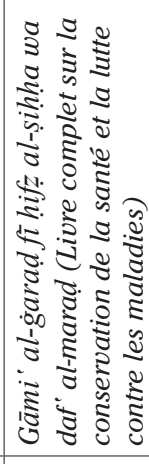 \\
\hline $\begin{array}{l}\mathscr{\Perp} \\
\stackrel{\mathscr{E}}{\tilde{\sigma}}\end{array}$ & 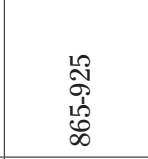 & $\begin{array}{l}\infty \\
\infty \\
\infty \\
\infty \\
\infty\end{array}$ & $\begin{array}{l}\mathscr{\&} \\
\stackrel{0}{g} \\
\dot{g}\end{array}$ & 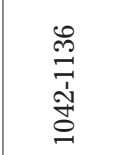 & $\begin{array}{l}\stackrel{\infty}{\stackrel{\Im}{\Xi}} \\
\dot{\Xi}\end{array}$ & 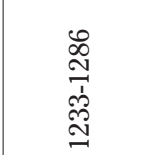 \\
\hline 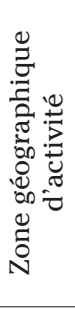 & 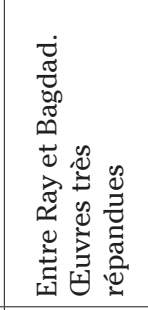 & 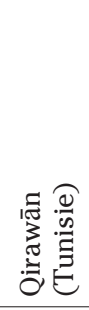 & 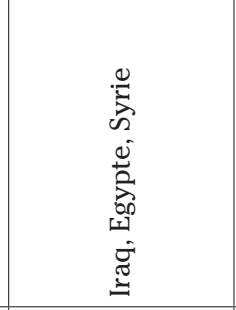 & 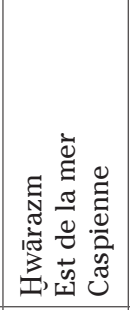 & 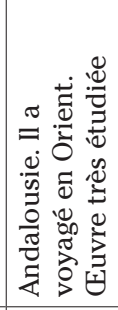 & 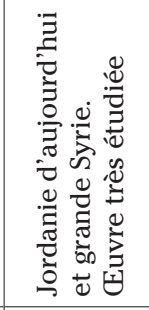 \\
\hline ह & 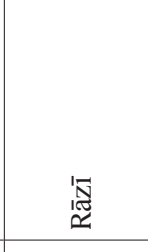 & 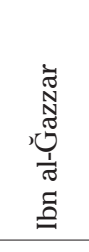 & 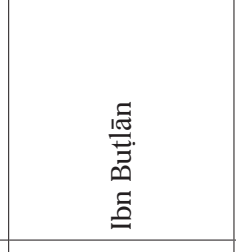 & 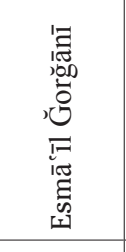 & 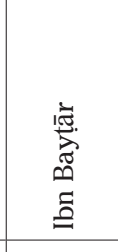 & 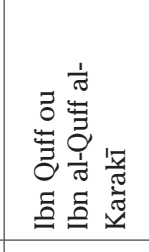 \\
\hline & - & N & $m$ & $\theta$ & مـ & 0 \\
\hline
\end{tabular}


Annexe 3 - La variole et la rougeole, maladies virales

\begin{tabular}{|c|c|c|}
\hline Caractéristiques & $\begin{array}{l}\text { La variole } \\
\text { (petite vérole) } \\
\text { anglais : smallpox } \\
\text { arabe : al-ğgudarī } \\
\text { persan : abeleh }\end{array}$ & $\begin{array}{l}\text { La rougeole } \\
\text { anglais : measles } \\
\text { arabe : al-hasba } \\
\text { persan : sorhak }\end{array}$ \\
\hline Agent viral & Poxvirus & $\begin{array}{l}\text { Paramyxovirus } \\
\text { Mirobillivirus }\end{array}$ \\
\hline $\begin{array}{l}\text { Immunisation post- } \\
\text { infection }\end{array}$ & Oui & Oui \\
\hline Contagion & +++ & +++ \\
\hline Âge & & Enfant à partir de 5-6 mois \\
\hline Incubation & 10 à 14 jours & - \\
\hline Durée de la fièvre & Fièvre forte quelques jours & Fièvre forte quelques jours \\
\hline $\begin{array}{l}\text { Symptômes fré- } \\
\text { quents }\end{array}$ & $\begin{array}{l}\text { Frissons, maux de tête, } \\
\text { nausée }\end{array}$ & Idem \\
\hline Peau & $\begin{array}{l}\text { Vésicules }(3 \mathrm{~mm}) \\
\text { puis pustules }\end{array}$ & $\begin{array}{l}\text { Éruption morbilleuse : exan- } \\
\text { thème }\end{array}$ \\
\hline Corps & $\begin{array}{l}\text { Visage } \\
\text { Paume de la main } \\
\text { Gravité selon étendue } \\
\text { Si hémorragique => grave }\end{array}$ & $\begin{array}{l}\text { En premier, visage } \\
\text { Puis, tout le corps } \\
\text { Prurit fréquent } \\
\text { (démangeaisons) }\end{array}$ \\
\hline $\begin{array}{l}\text { Signe pathognomo- } \\
\text { nique }\end{array}$ & & $\begin{array}{l}\text { Signe de Koplik: } \\
\text { taches bleutées dans la } \\
\text { bouche } \\
\text { Fugace ( } 24 \text { heures) }\end{array}$ \\
\hline
\end{tabular}


Soigner l'enfant dans les textes médicaux arabes et persans du Moyen Âge

Annexe 4 - Comparaison de la rougeole et de la variole d'après le traité de Rāzī (mort en 925)

\begin{tabular}{|c|c|c|}
\hline $\begin{array}{l}\text { Existence ou non de } \\
\text { spécificité }\end{array}$ & $\begin{array}{l}\text { La variole } \\
\text { (petite vérole) } \\
\text { anglais : smallpox } \\
\text { arabe : al-ğudari } \\
\text { persan : abeleh }\end{array}$ & $\begin{array}{l}\text { La rougeole } \\
\text { anglais : measles } \\
\text { arabe : al-hasba } \\
\text { persan : sorhak }\end{array}$ \\
\hline & fièvre continue & fièvre continue \\
\hline & évanouissement & évanouissement \\
\hline Spécifique *** & grande douleur dans le dos & $\begin{array}{l}\text { douleur (plus légère) dans } \\
\text { le dos }\end{array}$ \\
\hline Spécifique * & $\begin{array}{l}\text { inquiétude } \\
\text { tristesse }\end{array}$ & $\begin{array}{l}++ \text { inquiétude intense } \\
++ \text { tristesse intense }\end{array}$ \\
\hline Spécifique * & frayeurs pendant le sommeil & $\begin{array}{l}++ \text { frayeurs intenses pendant } \\
\text { le sommeil }\end{array}$ \\
\hline Spécifique & visage enflé, rouge & rougeur brillante \\
\hline Spécifique & & rougeur intense des gencives \\
\hline $\begin{array}{l}\text { Particularités } \\
\text { légères }\end{array}$ & démangeaisons dans le nez & - \\
\hline$/ /$ & $\begin{array}{l}\text { picotements sur le corps } \\
\text { corps lourd }\end{array}$ & - \\
\hline // & yeux rouges & - \\
\hline$/ /$ & $\begin{array}{l}\text { douleur à la gorge et la } \\
\text { poitrine }\end{array}$ & - \\
\hline$/ /$ & $\begin{array}{l}\text { difficulté légère de la respi- } \\
\text { ration }\end{array}$ & - \\
\hline // & salive épaisse & - \\
\hline$/ /$ & enrouement & - \\
\hline$/ /$ & douleurs, lourdeur de la tête & - \\
\hline
\end{tabular}


complémentaires pour découvrir le monde des soins à l'enfant en rapport avec l'entourage, la mère, la nourrice, la famille et les proches.

\section{Annexe 5 - Lexique sommaire}

\section{Termes médicaux}

Aphte : qula

Conservation de la santé : hiff̣ al-ṣiḥha

Lange : qimat

Ligaments : mafașil

Nature : al-tabī'a

Poils pubiens; 'āna

Semence : $z a r^{\circ}$

\section{Termes en relation avec la mère, la nourrice}

Femme enceinte : al-hubla

Femme qui allaite : al-murdic'a

Sage-femme : al-qābila

Sevrage : al-fitām

\section{Âges de la vie}

Adolescent : $a l-s \bar{a} b b$

Croissance : al-namā

Enfant jusqu'à deux ans : al-tifl

Enfant de deux à douze ans : $a l-s ̦ a b \bar{l}$

Maturité : al-kuhula

Vieillesse : al-šuyuha

\section{Remèdes, aliments, pharmacopée}

Concombre : qit $\underline{\underline{a}}$

Cotonéaster : taranğebīn

Épine vinette : amīr barīs dans le texte bar bārīs

Graine de grenade : habb rummān

Lait : laban

Manne d'hedysarum : ̌̌s̆ hisht

Oxymel : siknă̆abīn

Pommes : tuffah

Poussin : furuğ

Présure : anfiha

Verjus : husșrum 


\section{RÉSUMÉ}

Cet article est consacré à l'enfant dans le monde arabo-musulman médiéval. L'étude se base sur trois catégories d'œuvres écrites en arabe ou en persan entre le $\mathrm{x}^{\mathrm{e}}$ et le $\mathrm{XIII}^{\mathrm{e}}$ siècle : des ouvrages sur la conservation de la santé (hifż al-șịhha), des livres médicaux dont des chapitres sont consacrés aux divers âges de la vie, ainsi que des textes de pharmacopée. Nous analysons principalement les écrits d'al-Rāzī (mort en 925), d'Ibn Buṭlān (mort en 1066), de Ğorğānī (mort en 1136), d'Ibn al-Bayțār (mort en 1248) et surtout d'Ibn alQuff (mort en 1286). Les premiers soins donnés au nourrisson sont des actes médicaux associant le corps et la psychologie, l'hygiène et la délicatesse; la musique et les mélodies font partie de ces attentions. L'étude sur le lait (de la mère, de la nourrice ou d'un mammifère) montre à quel point, pour les médecins, le lait établit le lien matériel et psychologique entre l'enfant en bas âge et son milieu de vie, ce qui explique l'importance essentielle du choix de la nourrice pour le bien-être de l'enfant. Cet article se termine par l'étude de la variole et de la rougeole, deux maladies infantiles fulgurantes et sévères pour les enfants, basée sur l'ouvrage de Rāzī qui en établit le diagnostic.

\section{ABSTRACT}

This article discusses the issue of childhood in the medieval Arab and Islamic civilization. It is based on a series of texts written in Arabic or Persian between the $10^{\text {th }}$ and $13^{\text {th }}$ centuries, relating to health preservation and disease prevention (hif al-sihha), to medical care depending on the age of the individual and to pharmacopoeia. We analyse in particular the books of al-Rāzī (died 925), Ibn Butlān (died 1066), Ğorğān̄̄ (died 1136), Ibn al-Baytāōr (died 1248) and Ibn al-Quff (died 1286). We study the conditions of the survival and well-being of the child from the point of view of nutrition and daily care which associates physical and psychological cares - music and melodies are part of this process. The choice of the wet nurse and the quality of the milk were essential in early childhood. For physicians, the milk (from the mother or the wet nurse or a mammal) established a real union and continuity between the infant or the very young child and his milieu. Consequently, the quality of milk and the choice of the wet nurse were essential in early childhood. Among childhood diseases, smallpox and measles, two dramatic and severe illnesses, are discussed. This last study is based on The book of the measles and the smallpox written by Rāzi who established the differential diagnosis of these two diseases. 